\section{POS0636 INFLUENCE OF DEMOGRAPHIC AND DISEASE RELATED FACTORS ON EFFICACY OF INFLIXIMAB OR GOLIMUMAB IN RHEUMATOID ARTHRITIS. A META-ANALYSIS ON RANDOMIZED PLACEBO- CONTROLLED TRIALS}

M. A. Sparfel ${ }^{1}$, S. Derolez ${ }^{1}$, J. Law-Wan ${ }^{1}$, N. Azzopardi ${ }^{2}$, P. Goupille ${ }^{1}$, D. Mulleman ${ }^{1}, \mathrm{~T}$. Bejan-Angoulvant ${ }^{3} .{ }^{1}$ Université de Tours, EA 7501, Service de Rhumatologie CHRU de Tours, Tours, France; ${ }^{2}$ Université de Tours, EA 7501, ERL CNRS 7001, Tours, France; ${ }^{3}$ Université de Tours, EA 4245, Service de Pharmacologie Clinique, CHRU de Tours, Tours, France

Background: TNF inhibitors have changed the course of rheumatoid arthritis (RA). Yet, detailed analysis on factors influencing clinical response to TNF inhibitors in RA is lacking.

Objectives: Herein we aimed at studying the impact of demographics and disease-related factors on therapeutic response to golimumab and infliximab in RA Methods: Randomized clinical trials (RCTs) that evaluated golimumab and infliximab versus placebo or conventional therapy were sought. We selected the following factors: age, sex, ethnicity, body mass index (BMI), smoking status, physical activity, disease duration, disease activity at baseline, presence of auto-antibodies. We studied the impact of these factors on clinical response using firstly aggregate data in a Mantel-Haenszel random effects model, and secondly individual data in a multivariate regression model.

Results: Individual data from 8 RCTs, 2 on infliximab $(n=1477)$ and 6 on golimumab (total $=3041$ ) were obtained. In the aggregate model analysis, none of the selected factors had a significant impact on clinical response. In the multivariate analysis, male sex and physical activity were significantly associated with a lower DAS28-CRP after 6 months of treatment (regression coefficients -0.264 $(p<0.001)$ and $-0.193(p=0.004)$ respectively), while a high initial DAS28-CRP was significantly associated with a higher DAS28-CRP (regression coefficient $0.579(p<0.001))$. The baseline disease activity was the only significant interaction factor with the effect of the treatment.

Conclusion: Male gender and practicing physical activity are associated with lower disease activity 6 months after golimumab or infliximab initiation. High baseline disease activity significantly influences negatively the effect of the treatment on disease activity score.

Acknowledgements: This study, carried out under YODA Project 2018-2931, used data obtained from the Yale University Open Data Access Project, which has an agreement with JANSSEN RESEARCH \& DEVELOPMENT, L.L.C. The interpretation and reporting of research using this data are solely the responsibility of the authors and does not necessarily represent the official views of the Yale University Open Data Access Project or JANSSEN RESEARCH \& DEVELOPMENT, L.L.C.

Disclosure of Interests: Marc-Antoine SPARFEL: None declared, Sophie Derolez: None declared, Johan Law-Wan: None declared, Nicolas Azzopardi: None declared, Philippe Goupille Speakers bureau: Abbvie, Biogaran, BMS, Hospira, Janssen, MSD, Pfizer, Sanofi-Genzyme, UCB, Consultant of: Abbvie, Biogaran, BMS, Hospira, Janssen, MSD, Pfizer, Sanofi-Genzyme, UCB, Grant/research support from: Clinical trials sponsored by Abbvie, Roche, BMS, Boehringer, Lilly, Novartis, Pfizer, UCB, Janssen and MSD. Invitation to an international congresses by MSD, Roche, BMS and Abbvie, Denis Mulleman Speakers bureau: Pfizer and Novartis, Consultant of: Pfizer and Novartis, Grant/ research support from: Invitation to an international congress by Janssen-Cilag, Theodora Bejan-Angoulvant: None declared

DOI: 10.1136/annrheumdis-2021-eular.3565

\section{\begin{tabular}{|l|l}
\hline POS0637 INCIDENCE AND DETERMINANTS ASSOCIATED \\
\hline
\end{tabular} WITH RETRANSITIONING FROM BIOSIMILAR SB4 TO ORIGINATOR ETANERCEPT}

R. Meijboom ${ }^{1,2}$, H. Gardarsdottir ${ }^{2,3,4}$, M. Becker ${ }^{1,5}$, S. Ten Wolde ${ }^{6}$, T. Egberts ${ }^{2,3}$, T. Giezen ${ }^{1,2,5}$. ${ }^{1}$ Pharmacy Foundation of Haarlem Hospitals, Pharmacy Foundation of Haarlem Hospitals, Haarlem, Netherlands; ${ }^{2}$ Utrecht Institute for Pharmaceutical Sciences, Division of Pharmacoepidemiology \& Clinical Pharmacology, Utrecht, Netherlands; ${ }^{3}$ University Medical Center Utrecht, Department of Clinical Pharmacy, Utrecht, Netherlands; ${ }^{4}$ University of Iceland, Department of Pharmaceutical Sciences, Reykjavik, Iceland; ${ }^{5}$ Spaarne Gasthuis, Department of Clinical Pharmacy, Haarlem and Hoofddorp, Netherlands; ${ }^{6}$ Spaarne Gasthuis, Department of Rheumatology, Haarlem, Netherlands

Background: The market entry of the etanercept biosimilar SB4 (BS-ETA) reduced prices; and, therefore, many patients in clinical practice are transitioned from originator etanercept (OR-ETA) to BS-ETA. However, previous studies demonstrated that $2.7-17.1 \%$ of patients who transitioned from OR-ETA to BS-SB4, retransitioned to OR-ETA (i.e. restarted originator), which might reduce the (financial) benefits of biosimilars. Insight in the incidence of retransitioning and characteristics of patients who are most likely to retransition, can provide lessons to clinicians for successful introduction of biosimilars.

Objectives: To assess the incidence of retransitioning from BS-ETA to OR-ETA in patients with a rheumatic disease (RD) and to identify determinants thereof Methods: All patients diagnosed with RD who transitioned in 2016 from OR-ETA to BS-ETA in a Dutch general teaching hospital (the Spaarne Gasthuis, Haarlem/Hoofddorp) were included in this cohort study. All patients were followed until retransitioning, switching to another biological, discontinuing of biological treatment death, loss to follow up or until censor date. The incidence of retransitioning and duration of BS-ETA use was assessed using the Kaplan-Meier method. Potential determinants for retransitioning, including age, gender, BS-SB4 dosing interval, use of other biologicals prior to OR-ETA, initiation or intensification of corticosteroids or immunomodula tors, hospitalisations and the number of outpatient visits to the rheumatology department, were assessed in a nested case control study, using (multivariate) conditional logistic regression.

Results: In total, 342 patients (median age 57.8 years, $53.5 \%$ females, median follow-up 2.7 years) were included. $9.4 \%$ of patients had retransitioned to OR-ETA one year after transitioning. Additionally, one year after transitioning $69.7 \%$ of patients were still treated with BS-ETA, 3.8\% switched to other treatment and $17.1 \%$ discontinued all biological treatment. At the end of follow-up (median 2,7 years), 46 patients (13.5\%) retransitioned to OR-ETA; median time until retransitioning was 0.50 (IQR 0.98 ) years.

Univariate determinants for retransitioning included female gender (OR 2.37, $95 \% \mathrm{Cl} 1.18-7.74$ ), initiating or intensifying corticosteroids or immunomodulators (OR $3.24,95 \% \mathrm{Cl} 1.38-7.63$ ) and number of visits to the rheumatology department (OR 2.32, 95\% Cl 1.70-3.17). Based on the multivariate analysis, only the number of visits to the rheumatology department was associated with retransitioning (OR 2.19 95\% Cl 1.60-3.00), as demonstrated in Table 1.

Conclusion: When introducing BS-SB4 in clinical care, clinicians should anticipate on about one in seven patients retransitioning to OR-ETA. These patients might be identified prior to retransitioning based on their contacts to the rheumatology department. Information specifically aiming for their concerns might prevent them from retransitioning. However, more qualitative studies are needed to explore patients' underlying reasons for retransitioning, in order to improve the introduction of biosimilars in clinical care.

Table 1. Determinants for retransitioning

\begin{tabular}{|c|c|c|c|c|}
\hline & $\begin{array}{l}\text { Cases } \\
n=46\end{array}$ & $\begin{array}{c}\text { Controls } \\
n=184\end{array}$ & $\begin{array}{c}\text { OR } \\
\text { (univariate) } \\
95 \% \mathrm{Cl}\end{array}$ & $\begin{array}{c}\text { OR } \\
\text { (multivariate) } \\
95 \% \mathrm{Cl}\end{array}$ \\
\hline $\begin{array}{l}\text { Age, years (median, } \\
\text { IQR) }\end{array}$ & $59.0(16.5)$ & $56.5(22.3)$ & $1.01(0.98-1.03)$ & - \\
\hline \multicolumn{5}{|l|}{ Gender } \\
\hline Male & $15(32.6 \%)$ & $97(52.7 \%)$ & Ref & Ref \\
\hline Female & $31(67.4 \%)$ & $87(47.3 \%)$ & $2.37(1.18-7.74)$ & $1.36(0.60-3.07)$ \\
\hline \multicolumn{5}{|c|}{ BS-SB4 dosing interval (index date) } \\
\hline 7 days & $35(76.1 \%)$ & $129(70.1 \%)$ & Ref & - \\
\hline$>7$ days & $11(23.9 \%)$ & $55(29.9 \%)$ & $0.72(0.33-1.56)$ & \\
\hline \multicolumn{5}{|c|}{ Previous use other biological } \\
\hline No & $43(93.5 \%)$ & $172(93.5 \%)$ & Ref & - \\
\hline Yes & $3(6.5 \%)$ & $12(6.5 \%)$ & $1.00(0.27-3.74)$ & \\
\hline \multicolumn{5}{|c|}{ Initiation/ intensification corticosteroid/ immunomodulator } \\
\hline No & $35(76.1 \%)$ & $168(91.3 \%)$ & Ref & Ref \\
\hline Yes & $11(23.9 \%)$ & $16(8.7 \%)$ & $3.24(1.38-7.63)$ & $2.31(0.84-6.38)$ \\
\hline \multicolumn{5}{|l|}{ Hospitalisation } \\
\hline No & $41(89.1 \%)$ & $166(90.2 \%)$ & Ref & - \\
\hline Yes & $5(10.9 \%)$ & $18(9.8 \%)$ & $1.12(0.40-3.18)$ & \\
\hline $\begin{array}{l}\text { No. visits rheumatol- } \\
\text { ogy department }\end{array}$ & & & & Ref \\
\hline (median, IQR) & $2(2)$ & $0(1)$ & $2.32(1.70-3.17)$ & $2.19(1.60-3.00)$ \\
\hline
\end{tabular}

Disclosure of Interests: None declared

DOI: 10.1136/annrheumdis-2021-eular.3636

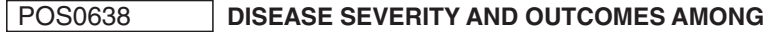 PATIENTS WITH RHEUMATOID ARTHRITIS WHO RECEIVE A NEWLY APPROVED BIOLOGIC: REAL- WORLD US EXPERIENCE WITH SARILUMAB FROM THE ACR RISE REGISTRY}

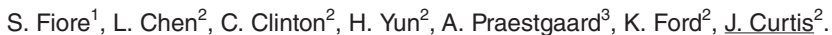
${ }^{1}$ Sanofi, Sanofi, Bridgewater, United States of America; ${ }^{2}$ University of Alabama at Birmingham, Division of Clinical Immunology and Rheumatology, Birmingham, United States of America; ${ }^{3}$ Sanofi, Sanofi, Cambridge, United States of America 